\title{
Investigate Evaluation of Oxidative Stress and Lipid Profile in STZ-Induced Rats Treated with Antioxidant Vitamin
}

\author{
Abdella Emam Abdella Baragob ${ }^{1 *}$, Waleed Hassan Al Malki ${ }^{1}$, \\ Hassan Elsiddig Hassan Farag Alla ${ }^{2,3}$, Asim Ibrahim4, Salwa Khojali Muhammed ${ }^{5}$, \\ Samia Abdella ${ }^{6}$ \\ ${ }^{1}$ Department of Pharmacology and Toxicology, Faculty of Pharmacy, Umm Al Qura University, Makkah, \\ Saudi Arabia \\ ${ }^{2}$ Department of Public Health, Health Sciences College at Al-lieth, Umm Al Qura University, Makkah, \\ Saudi Arabia \\ ${ }^{3}$ Department of Histopathology and Cytology, College of Medical Laboratory Science, Sudan University of \\ Science and Technology, Khartoum, Sudan \\ ${ }^{4}$ Department of Pharmaceuticalchemistry, Faculty of Pharmacy, Umm Al Qura University, Makkah, Saudi Arabia \\ ${ }^{5}$ Veterinary Research Institute, Department of Pharmacology, Khartoum, Sudan \\ ${ }^{6}$ Veterinary Research Institute, Department of Biochemistry, Khartoum, Sudan \\ Email: aeabaragob@yahoo.com,whmalki@uqu.edu.sa, Hassan.elsiddig@yahoo.com, \\ asimYousif2005@yahoo.com, Salwamuhamed@hotmail.com, samiah11@gmail.com
}

Received 24 January 2014; revised 25 February 2014; accepted 8 March 2014

Copyright (C) 2014 by authors and Scientific Research Publishing Inc.

This work is licensed under the Creative Commons Attribution International License (CC BY).

http://creativecommons.org/licenses/by/4.0/

(c) (i) Open Access

\section{Abstract}

The objective of this study was designed to investigate, evaluate the effect of vitamin $E$ on streptozotocin (STZ)-induced diabetic rats by showing significant changes in blood glucose, water, food intake, lipid profile, serum urea and ceratinine level, and antioxidant enzyme parameters activity. Streptozotocin (STZ)-induced toxicity was studied in male Waster rats; each divided into four groups: G1, GII, GIII, and GIV. Control rats GI, rats treated with vitamin E (GII), STZ-induced diabetic rats (GIII), and STZ-induced diabetic rats treated with vitamin E (G1V). Moreover, vitamin E reduced $(p<0.05)$ blood glucose and urea, thus, our study improved the lipid profile (reduced the serum levels of amount of total cholesterol, LDL, VLDL, cholesterol and triacyglycerols, and increased HDL cholesterol) and increased total amount protein in STZ-induced diabetic rats (GIV). Vitamin prevented modification in the activity of superoxide dismutase (SOD) and glutathione peroxidase (GSX-PX) and in the concentration of the lipid hydroperoxide. Finally the study suggested that vitamin E improved hyperglycaemia and dyslipidaemia while inhibiting the progression of oxidative stress in STZ-induced diabetic rats.

${ }^{*}$ Corresponding author.

How to cite this paper: Baragob, A.E.A., et al. (2014) Investigate Evaluation of Oxidative Stress and Lipid Profile in STZ-Induced Rats Treated with Antioxidant Vitamin. Pharmacology \& Pharmacy, 5, 272-279. 


\section{Keywords}

\section{Investigate; Lipid; Profile; STZ; Oxidative Stress; Vitamin E}

\section{Introduction}

Diabetes mellitus is a global disease, found in all nations of the world. The number of patients with diabetes worldwide prevalence is expected to double between 1994 and 2025 to affect more than 225 million people [1] [2].

The present work of the hypoglycemic investigation was carried out with production of reactive oxygen species (ROS) and the oxidative stress, which not only induced as alteration in the cellular redox state in the presence of chronic hyperglycaemia, but also reduce the ability of tissues to used carbohydrates, which finally result in disturbances in the metabolism of protein and fat [3].

Whoever, this process is accompanied by an imbalance between the oxidant and also antioxidant status, such as elevating the result in production of ROS and reducing antioxidant defense system [4]-[6].

This experimental test showed that data have been suggested that chronic high blood glucose levels lead to formation of ROs, within different mechanisms such as glucose autoxidation, the oxidation of protein [7] [8] whatever; thus exacerbating oxidative stress. Therefore, the integrated characteristic of streptozotocin induces experimental insulin-dependent diabetes mellitus (type 1) in animal within its cytotoxic effects on pancreatic beta-cells via a mechanism accompanied with the generation of ROS [9] [10]. It results in a deficiency of insulin, which act as a diabetogenic agent [11].

Diabetes mellitus is a chronic metabolic risk disorder which is characterized by an increased risk of mortality and prevalence of cardiovascular disease. Atherosclerotic cardiovascular disease is the main source of mortality and morbidity in diabetes patients [12] [13].

Whoever, many studies have showed that hyperglycaemia in diabetes is responsible for oxidative stress; it has been explained that the nutritional supplementation of antioxidant might decrease the oxidative stress, then lead to protecting tissues from ROS damage [14].

In this study, treatment with antioxidant vitamins mainly vitamin E, is of great interest, with result in the potential protective activity of antioxidants, so vitamin E used may prevent the development of diabetes mellitustype 1 [7] [15] [16].

The aim of this study was to explain the effect of vitamin E on oxidative stress, the renal dysfunction, measuring urea and creatinine level, as well as the lipid profile, in normal and streptozotocin-induced diabetic rats.

\section{Marerial and Methods}

\subsection{Expermental Animals}

In this experiment, rats male of Wister weighting $200 \pm 250$ g were used. Rats were housed under a condition within $25^{\circ} \mathrm{C} \pm 3^{\circ} \mathrm{C}$, humidity of $55 \% \pm 2 \%$, under a constant $12 \mathrm{~h}$, food and water were available.

The animals allotted in four experimental groups $(n=8)$ as follows; group 1(G1): control rats; gruop11 (G11): vitamin E; group111 (G111): STZ-induced diabetic rats and group IV (IV): STZ-induced diabetic rats treated with vitamin $\mathrm{E}$.

Streptozotocin dissolved in citrate-phosphate buffer at $\mathrm{pH} 4.5$, was administered in a single dose of $60 \mathrm{mg} / \mathrm{kg}$ body weight; i.p. Hyperglycaemia was measured using a blood glucose (BG) monitor (Behringer Mannheim, Eli lilly Ltd.,) $48 \mathrm{~h}$ after STZ injection. STZ-treated rats with fasting blood $>250 \mathrm{mg} / \mathrm{dl}$ were regarded as diabetic and selected for this experiment.

Three days after STZ administration, vitamin E ( $\alpha$-tocopherolacetate) was administered intragastrically (gavage) once a week, at the dose of $440 \mathrm{IU} / \mathrm{kg}$ body weight (equivalent to $440 \mathrm{mg} / \mathrm{kg}$ body weight) for 30 days [17]. Food and water were measured daily. Body weight (g) was notated weekly. After 30 days of the experiment all rats were fasted for $12 \mathrm{~h}$; anaesthetized with certaminchloridrate $0.1 \mathrm{ml} / 100 \mathrm{~g}$ body weight of $10 \%$ then the rats killed by decapitation and blood was collected and centrifuged at $6000 \mathrm{rpm}$ for 15 min, to separate the serum. 


\subsection{Test Procedures of Glycaemia and Dyslipidaemia}

Under aseptic conditions spectrophotometric methods with commercial enzymatic kits were used to determine the biochemical parameters (CELM—Modern Laboratory Equipment Company. Sao Paulo, Brazil).

For determination of the serum glucose enzymatically using the glucose and peroxidase method [18]:

The concentration of the serum of the total cholesterol was determined by enzymatic method using cholesterol ester/oxidase, serum high-density Lipoprotein (HDL) content was precipitated of the very low-density lipoprotein (VLDL) and low density lipoproteins (LDL) withphosphotungastic acid and $\mathrm{MgCl}_{2}$. LDL cholesterol and VLDL-cholesterol values were calculated according to Friedewald'sformula [19]. The levels of triacylglycerol in the serum were estimated enzymatically after hydrolysis by lipoprotein lipase in glycerol, then to glycerol phosphate and then to dihydroxyacetone phosphate and $\mathrm{H}_{2} \mathrm{O}_{2}$, moreover; in the presence of peroxidase was converted to aminophenazone.

The determined of the level serum urea in the presence of urease, resulting in $\mathrm{CO}_{2}$ and ammonia.

Also the addition of phenol-hypochloride leads to an indophenol-blue complex with absorbance at $600 \mathrm{~nm}$.

Creatinine assayed by reaction with picric acid in alkaline buffer to form a yellow-orange complex. The color intensity, determined at $500 \mathrm{~nm}$, was proportional to the creatinine concentration in the sample.

Total protein was identified in the presence of biuret reagent

\subsection{Identification of Oxidative Stress Markers}

Lipid hydroperoxide (HP) was identified through the oxidation of ferrous ion, which in the presence of xylenol orange lead to the formation of the $\mathrm{F}^{3}$ —xylenol orange complex, which was measured at $560 \mathrm{~nm}$ [20].

Superoxide dismutase (SOD, E.C.15,1.1) activity was assayed as described:

Elesewhere [21], through the inhibition of the reduction of nitro blue tetrazolium (NBT) in the presense reduced nicotinamide adenine dinucleotide (NADH) and phenazine. The amount of enzyme that gave 50\% inhibition of NBT reduction/mg protein was taken as one of enzyme activity.

Glutathione peroxidase (GSH-Px, 1.11,1.9) activity was determined indirectly by determined the consumption of NADPH during the reduction of oxidized glutathione (GSSG) in a reaction of catalyzed by glutathione reductase, one unit of enzyme was defined as the amount required to oxidize $1 \mu \mathrm{mdGSH} / \mathrm{min}$, which corresponded to $0.5 \mu$ mole NADPH oxidized/min [22].

\subsection{Statistical Analysis}

Data were expressed as means \pm standard deviation (S.D) Tukey analysis was used to test for differences among the means when analysis of variance (ANOVA) indicated a significant $\mathrm{p}$ value $<0.05$ [23].

\section{Results}

Diabetic animal showed a significant $(\mathrm{p}<0.005)$ reduce in body weight (G111) in a compared with normal rats (G1). Dietary vitamin E supplementation (GIV) result to a significant $(\mathrm{p}<0.05)$ increase body weight; moreover, vitamin $\mathrm{E}$ not influence the body weight in normal rats (G11) in compared to the control rats. Diabetic rats showed significantly $(\mathrm{p}<0.05)$ higher intake of food and water when compared with the control group. Food intake was reducing in group IV, along with water intake, when compared with group 111. Serum glucose was significantly elevated $(\mathrm{p}<0.05)$ in diabetic animal compared with normal control rats. Vitamin E, orally administered, also result to a marked reduce $(\mathrm{p}<0.05)$ in serum glucose of diabetic rats $(\mathrm{G} 1 \mathrm{~V})$ at the final of the study.

Morever, supplementation with vitamin E in normal rats (G11) not showed any significant $(p<0.05)$ effect on the fasting serum glucose level in the study.

The modifications in the lipid profile of normal and diabetic rats are given in Table 1. Untreated diabetic rats were characterized by a significant increase level of the total cholesterol, LDL cholesterol, VLDL cholesterol and triacylglycerids, compared with the normal animal. Diabetic rats treated with vitamin E (G1V) in which observed approximately normal levels of total cholesterol, VLDL cholesterol and tricylglycerols. Dietary vitamin E caused a significant decrease in the serum level of LDL cholesterol, when compared with diabetic rats (G111). Significatly $(\mathrm{p}<0.05)$ reduce levels of serum HDL cholesterol were observed in diabetic rats when it's compared with the non-diabetic rats (G1). Oral administration of vitamin E to diabetic rats showed a significantly 
increase serum HDL cholesterol, when compared with diabetic rats.

Lipid hydroperoxide increase in diabetic rats, while the GSH-Px and SOD activity decreased significantly in comparison to normal control rats. The treatment of diabetic rata with vitamin E (G1V) result in a significant decrease in serum levels of lipid hydroperoxide, so the antioxidant enzyme activity was significantly higher in vitamin E-treated diabetic group (G1V) when compared to the untreated rats. Vitamin E administration to normal rats not alter the activity of GSH-Px or SOD (Table 2).

The concentration of the serum urea and creatinine was significantly higher $(\mathrm{p}<0.05)$ in STZ-diabetic rats (G111). Diabetic rats treated with vitamin E (GIV) in which observed a significant decrease in the level of urea and creatinine (Table 3). The total protein level result in a marked reduction in the serum of diabetic rats (G111), a significant increase in total protein content was observed after the treatment with vitamin E (G1V).

Table 1. Effect of the administration of vitamin Eon profile in normal an STZ-induced diabetic rats after 30 days.

\begin{tabular}{cccccc}
\hline Group & $\begin{array}{c}\text { Total cholesterol } \\
\mathrm{mmol} / \mathrm{L}\end{array}$ & $\begin{array}{c}\text { LDL Cholesterol } \\
\mathrm{mmol} / \mathrm{L}\end{array}$ & $\begin{array}{c}\text { VLDL Cholesterol } \\
\mathrm{mmol} / \mathrm{L}\end{array}$ & $\begin{array}{c}\text { Triacylglycerol } \\
\mathrm{mmol} / \mathrm{L}\end{array}$ & $\begin{array}{c}\text { HDL } \\
\text { Cholesterol/mmol/L }\end{array}$ \\
\hline G1 & $2.65 \pm 65 \mathrm{a}$ & $0.96 \pm 0.27 \mathrm{a}$ & $0.40 \pm 0.04 \mathrm{a}$ & $0.88 \pm 0.08 \mathrm{a}$ & $1.31 \pm 0.29 \mathrm{bc}$ \\
$\mathrm{G} 11$ & $2.80 \pm 27 \mathrm{a}$ & $0.81 \pm 0.26 \mathrm{a}$ & $0.38 \pm 0.03 \mathrm{a}$ & $0.86 \pm 0.08 \mathrm{a}$ & $1.61 \pm 0.24 \mathrm{~b}$ \\
$\mathrm{G} 111$ & $7.01 \pm 43 \mathrm{~b}$ & $5.66 \pm 0.41 \mathrm{c}$ & $0.71 \pm 0.07 \mathrm{~b}$ & $1.55 \pm 0.16 \mathrm{~b}$ & $0.64 \pm 0.12 \mathrm{a}$ \\
$\mathrm{GV}$ & $2.99 \pm 18 \mathrm{a}$ & $1.48 \pm 0.16 \mathrm{~b}$ & $0.38 \pm 0.04 \mathrm{a}$ & $0.86 \pm 0.09 \mathrm{a}$ & $1.12 \pm 0.16 \mathrm{c}$ \\
\hline
\end{tabular}

The above number mention indicated values which given as mean \pm SD for eight rats in each group statistical evaluation was carried out using ANOVA followed by Tukey values not sharing a common superscript letter differ significantly at $p<0.05$, G1: control; G11: vitamin E; G111: diabetic; GV: diabetic + vitamin E.

Table 2. Effect of the administration of vitamin $\mathrm{E}$ on lipid hydroperoxide (HP) concentration and glutathione peroxide (GSH-Px) and superoxide dismutase (SOD) activities in normal and STZ-induced diabetic rats after 30 days of treatment.

\begin{tabular}{cccc}
\hline Group & Hp (mmol/L) & GSH-Px $(\mathrm{u} / \mathrm{mL})$ & SOD U/mg protein \\
\hline G1 & $0.29 \pm 0.01 \mathrm{a}$ & $142.22 \pm 26.37 \mathrm{c}$ & $21.10 \pm 2.66 \mathrm{~b}$ \\
G11 & $0.29 \pm 0.01 \mathrm{a}$ & $139.87 \pm 20.78 \mathrm{c}$ & $21.14 \pm 3.34 \mathrm{~b}$ \\
G111 & $0.61 \pm 0.03 \mathrm{c}$ & $75.64 \pm 18.15 \mathrm{a}$ & $10.37 \pm 1.96 \mathrm{a}$ \\
GV & $0.42 \pm 0.03 \mathrm{~b}$ & $97.99 \pm 20.47 \mathrm{~b}$ & $21.25 \pm 2.50 \mathrm{~b}$ \\
\hline
\end{tabular}

The above number mention are indicated as values which given as mean $\pm \mathrm{SD}$ for eight rats group. Statistical evaluation was carried out using ANOVA followed by Tukey values not sharing a common superscript letter differ significantly at $\mathrm{p}<0.05$. G1: control; G11: vitamin E; G111: diabetic + vitamin E.

Table 3. Effect of the administration of vitamin E on serum concentration of creatinine, urea and total protein in normal and STZ-induced diabetic rats, after 30 days of treatment.

\begin{tabular}{cccc}
\hline Group & Creatinine $(\mathrm{Ummol} / \mathrm{L})$ & Urea $(\mathrm{mmol} / \mathrm{L})$ & Total protein $(\mathrm{g} / \mathrm{L})$ \\
\hline G1 & $62.48 \pm 8.7 \mathrm{a}$ & $8.84 \pm 1.76 \mathrm{a}$ & $73.5 \pm 8.0 \mathrm{~b}$ \\
G11 & $161.82 \pm 14.96 \mathrm{~b}$ & $7.59 \pm 0.92 \mathrm{a}$ & $72.0 \pm 8.0 \mathrm{~b}$ \\
G111 & $192.71 \pm 14.36 \mathrm{c}$ & $16.63 \pm 1.53 \mathrm{~b}$ & $43.0 \pm 7.0 \mathrm{a}$ \\
GV & $176.0 \pm 16.72 \mathrm{c}$ & $9.78 \pm 1.63 \mathrm{a}$ & $73.0 \pm 5.0 \mathrm{~b}$ \\
\hline
\end{tabular}

The above mention numbers indicated values given as mean $\pm \mathrm{SD}$ for eight rats in each group. Statistical evaluation was carried out for common superscript letter differ significantly at $\mathrm{p}<$ 0.05. G1: control; G11: vitamin E; G111: diabetic; G1V: diabetic + vitamin. 


\section{Discussion}

Our study investigated and evaluated the effect of treatment with vitamin $\mathrm{E}$ on the lipid profile oxidative stress and renal outcome of STZ-induced diabetes in rats (Insulin dependent diabetes mellitus-IDDM type 1).

The present study noticed that vitamin E lowered the glycaemic index in diabetes, which was joined with previous studies.

Vitamin E was able to lower the food and water intake in diabetic rats. This could be due to the correction of glycaemia, which was associated with an improved metabolic state in those animals.

The efficacy of vitamin E protects against the body weight loss, which could be attributed to its ability to reduce hyperglycaemia. This may be achieved via the inhibition of hepatic gluconeogenesis and glucose output from the liver, which is accompanied with the suppression of lipolysis in adipose tissue [24]. However; these consist with the fact that vitamin E caused a lowering in the level of circulating glucagon in diabetic rats [25].

The capacity of vitamin E for reducing serum triacyglycerols and VLDL may be attributed to its protection of membrane-bound lipoprotein lipase against lipid peroxide [26].

The antihyperglycaemic effect of vitamin $\mathrm{E}$ and hence the improved diabetic state may lead to a reduction in the concentration of VLDL and consequently the LDL level [27].

This study demonstrated that the administration of vitamin E was able to prevent a reduction in HDL during the experiment period in STZ-induced rats. Moreover; vitamin E was able to be protective against atherosclerosis and cardiovascular disease. So there was a negative correlation between atherosclerotic cardiovascular disease and the plasma HDL level [28], the mechanism could involve reverse cholesterol transport.

Oral administration of vitamin E increased serum HDL (G11). Concentration of HDL and vitamin E could be that the antioxidant vitamin increased lecithin: cholesterol acyltransferase (LCAT) activity. Whatever raises the rate of cholesterylestertransfer for within of HDL lipoprotein. Furthermore, LCAT activity may increase the transport of cholesterol ester by from peripheral tissue to liver and stimulate the production and secretion of HDL for circulating [29].

The main characteristic symptoms in STZ-induced diabetic rats showed significant increase in blood glucose (hyperglycaemia), water intake (polydipsia), food intake (hyperphagia), which accompanied with sever loss of body weight (Table 4) Increased water and food consumption result in a direct accumulation of glucose in blood and increase in the urinary excretion of glucose [30].

The levels of plasma triacylglycerol, total cholesterol, very low-density lipoprotein (VLDL) while cholesterol and low-density lipoprotein (LDL) cholesterol, and the level of the high density lipoprotein (HDL) was reduced, shown in table (Table 1) indicated significant dyslipidaemia in untreated diabetic rats. In others several studies in animal or experimental diabetes same results were obtained [13] [31] [32], [explained diabetic dyslipidaemia and hyperglycaemia to be responsible of cardiovascular complications.

In the clam study, levels of lipid hydroperoxide increased, while there were a significantly activity decreased in diabetic rats (Table 2). Moreover; the indicated results were consistent with other reports of elevated levels in lipid hydroperoxide in theplasma diabetic subjects [33] [34], also in animal experimentaldiabetics [35].

In the present study, the STZ-induced diabetic nephropathy, showed a significantly increased in urea and creatinine levels in group (Table 2). Whatever; the impaired kidney function were consistent in the abnormally high levels of serum creatinine and urea [36]. An elevated urea concentration in diabetic rats is associated with highly protein catabolism [37] justification of positive results which correlation with hyperglycaemia and the

Table 4. Effect of treatment with vitamin E on body weight, food intake, water, and serum glucose concentration in normal and STZ-induced diabetic rats, after 30 days.

\begin{tabular}{ccccc}
\hline Group & Body weight (9) & Food intake g/rat day & Water intake( ml/rat day) & Glucose mmol/L \\
\hline G1 & $403.30 \pm 2064 \mathrm{~b}$ & $23.54 \pm 2.05 \mathrm{a}$ & $33.20 \pm 0.90 \mathrm{a}$ & $5.53 \pm 0.40 \mathrm{a}$ \\
G11 & $441 \pm 44.81 \mathrm{~b}$ & $27.51 \pm 1.72 \mathrm{~b}$ & $37 \pm 3.80 \mathrm{a}$ & $5.16 \pm 0.46 \mathrm{a}$ \\
G111 & $309.95 \pm 17.37 \mathrm{a}$ & $43.41 \pm 1.88 \mathrm{~d}$ & $180.55 \pm 25.80 \mathrm{c}$ & $17.29 \pm 2.18 \mathrm{~b}$ \\
G1V & $447.47 \pm 41.5 \mathrm{~b}$ & $35.20 \pm 0.50 \mathrm{c}$ & $88.37 \pm 6.38 \mathrm{~b}$ & $5.33 \pm 0.47 \mathrm{a}$ \\
\hline
\end{tabular}

The above numbers mention are given mean \pm SD for eight rats each group. Statistical evaluation was carried out using ANOVA followed by Tukey values a common superscript letter significantly at p < 0.05. G1: control; G11: vitamin E; G111: diabetic; G1V: diabetic + vitamin E. 
development of nephropathy. It has been showed that the metabolic test led to uncontrolled diabetes result in gluconeogenesis, so urea production, which is substantially enhanced in diabetes [38].

These results were considered similar with the reduction of the total serum protein levels that mentioned in STZ-induced diabetic rats (Table 2).

In conclusion, the administration of vitamin E decreased food and water intake, which result in lower creatinine and urea level, while hyperglycaemia and body weight, promoted the correction of lipid metabolism modification and protein levels in the STZ-induced diabetic rats. The increased levels in SOD and GSH-Px activity and reduced hydroperoxide levels could be due to the improvement of glycaemia promoted by vitamin $\mathrm{E}$. thus, imbalance between the generation of ROS and enzyme activity be controlled in diabetic rats.

\section{References}

[1] McGinly, C., Shafat, A. and Donnelly, A.E. (2009) Does Antioxidant Vitamin Supplementation Protect aganist Muscle Damage! Sports Medicine, 39, 1011-1032. http://dx.doi.org/10.2165/11317890-000000000-00000

[2] Coskunm, O., Kanter, M., Korkmaz, A. and Oter, S. (2005) Quercentin, a Flavonoid Antioxidant, Prevents and Protects Streptozocin-Induce Oxidative Stress and B-Cell Damage in Rat Pancreas. Pharmacological Research, 51, 235-241.

[3] Je, H.D., Shin, C.Y., Park, H.S., Huh, I.H. and Sohn, U.D. (2001) The Compaesion of Vitamin C and Vitamin E on the Protein Oxidation of Diabetic Rats. Journal of Autonomic Pharmacology, 21, 231-236. http://dx.doi.org/10.1046/j.1365-2680.2001.00226.x

[4] Baydas, G., Canatan, H. and Turkoglu, A. (2002) Comparative Analysis of the Protective Effect of Melatonin and Vitamin E on Streptozocin-Induced Diabetesmellitus. Journal of Pineal Research, 32, 225-230. http://dx.doi.org/10.1034/j.1600-079X.2002.01856.x

[5] Young, I.S., Tate, S., Lightbody, J.H., McMaster, D. and Trimble, E.R. (1995) The effects of desferrioxamine and ascorbate on oxidative stress in the streptozotocin diabetic rat. Free Radical Biology \& Medicine, 18, 833-840.

[6] Fakher, S.H., Djalali, M., Tabel, S.M.B., Zeraati, H., Javadi, E., Sadeghi, M., et al. (2007) Effect of Vitamin A, E, C, and Omega-3 Fatty Acids on Lipid Peroxidation in Streptozotocin-Induced Diabetic Rats. Iranian Journal of Public Health, 36, 58-63.

[7] Bonnefont-Rousselot, D., Bastard, J.P., Jaudon, M.C. and Delattre, J. (2000) Consequences of the Diabetic Status on the Oxidant/Antioxidant Balance. Diabetes \& Metabolism, 26, 162-176.

[8] Martim, A.C., Sanders, R.A. and Watkins, J.B. (2002) Diabetes Oxidative Stress, and Antioxidants: A Review. Journal of Biochemical and Molecular Toxicology, 17, 24-38. http://dx.doi.org/10.1002/jbt.10058

[9] Punitha, I.S.R., Rajendran, K. and Shirwaikar, A. (2005) Alcoholic Stem Extract of Cosciniumfenestratum Regulates Carbohydrate Metabolism and Improves Antioxidant Status in Streptozotocin—Innicotinamide-Induced Diabetic Rats. ECAM, 2, 375-381.

[10] Evelson, P., Sulsemihl, C., Villarreal, I., Llesuy, S., Rodriguez, R., Peredo, H., et al. (2005) Hepatic Morphological Changes and Oxidative Stress in Chronic Streptozotocin-Diabetic Rats. Annals of Hepatology, 4, 115-120.

[11] Szkudeslsiski, T. (2001) The Mechanism of Alloxan and Streptozotocin Action in B-Cells of the Rat Pancreases. Physiological Research, 50, 536-546.

[12] Bray, T.M. (2000) Dietary Antioxidants and Assessment of Oxidative Stress. Nutrition, 16, 578-580. http://dx.doi.org/10.1016/S0899-9007(00)00365-8

[13] Chertow, B. and Edwards, J.C. (2004) Advances in Diabetes for the Milennium: Vitamins and Oxidative Stress in Diabetes and Its Comolications. Medscape General Medicine, 6, 1-10.

[14] Sharma, A., Kharb, S., Chugh, S.N., Kakkar, R. and Singh, G.P. (2000) Evaluation of Oxidative Stress before and after Control of Glycemiaand after Vitamin E Supplementation in Diabetic Patients. Metabolism, 49, 160-162. http://dx.doi.org/10.1016/S0026-0495(00)91117-X

[15] Knekt, P., Reunanen, A., Marniemi, J., Leino, A. and Aromaa A. (1999) Low Vitamin E Status Is a Potential Risk Factor for Insulin-Dependent Diabetes Mellitus. Journal of Internal Medicine, 245, 99-102. http://dx.doi.org/10.1046/j.1365-2796.1999.00416.x

[16] Matheus, A.S.M., Cobas, R.A. and Gomes, M.B. (2008) Dislipidemias No Diabetes Melito Tipo 1: Abordagem Atual. Arquivos Brasileiros de Endocrinologia \& Metabologia, 52, 334-339. http://dx.doi.org/10.1590/S0004-27302008000200021

[17] Konen, J.C., Summerson, J.H. and Kirk, J.K. (2000) Measurement Feasibility of Advanced Glycated End-Products from Skin Samples after Antioxidant Vitamin Supplementation in Patients with Type 2 Diabertes. The Journal of Nutrition Health and Aging, 4, 81-85. 
[18] Moura, R.A. (1982) Technicas de Laboratorio. 2nd Edition, Atheneu, Sao Apulo.

[19] Friedewald, W.T., Levy, R.I. and Fredrickson, D.S. (1972) Estimation of the Concentration of Low-Density Lipoprotein Cholesterol in Plasma, without Use of the Preparative Ultracentrifuge. Clinical Chemistry, 18, 499-502.

[20] Jiang, Z.Y., Woolard, A.C.S. and Wolf, S.P. (1991) Lipid Hydroperoxide Measurement by Oxidation of Fe². Lipids, 24, 861-869.

[21] Crouch, R.K., Gandy, S.C. and Kisey, G. (1981) The Inhibition of Islet Superoxide Dismutase by Diabetogenic Drugs. Diabetes, 30, 235-241. http://dx.doi.org/10.2337/diab.30.3.235

[22] Nakamura, W., Hojoda, S. and Hayashi, K. (1974) Purification and Properties of Rat Liver Glutathione Peroxidase. Biochimica et Biophysica Acta, 358, 251-261. http://dx.doi.org/10.1016/0005-2744(74)90455-0

[23] Zar, J.H. (1996) Bio Statistical Analysis. Prentice Ltd., New Jersey.

[24] Postic, C., Dentin, R. and Girard, J. (2001) Role of the Liver in the Control of Carbohydrate and Lipid Homeostasis. Atherosclerosis, 158, 1-12.

[25] Shami, M., Amin, A. and Adeghate, E. (2006) Vitamin Decreases the Hyperglucaonemia of Diabetic Rats. Annals of the New York Academy of Sciences, 1084, 432-441. http://dx.doi.org/10.1196/annals.1372.032

[26] Mendez, J.D. and Balderas, F. (2001) Regulation of Hyperglucaemia and Dyslipidemia by Exogenous L-Arginine in Diabetes Rats. Biochemistry, 83, 543-558. http://dx.doi.org/10.1016/S0300-9084(00)01192-5

[27] Guo, H., Saiga, A., Sato, M., Miyazawa, I., Shibata, M. and Takahata, Y. (2006) Antihyperglycaemic and Antioxidant Effect of Rutin, a Polyphenolic Flavonoid, in Streptozotocin-Induced Induced Diabetic Rats. Nordic Pharmacological Society, 98, 97-103.

[28] Stephen, N.J. (2004) Relationship between LDL, HDL, Blood Pressure and Atheroma Progression in the Coronaries. Current Opinion in Lipidology, 20, 491-496.

[29] Mackneess, M.I., Abbott, C.A., Arrol, S. and Durrington, Pn. (1993) The Role of High-Density Lipoprotein Oxidation. Biochemical Journal, 29, 829-834.

[30] Punithavathi, V.R., Anuthama, R. and Prince, P.S. (2008) Ombined with Naringin and Vitamin C Amelloratesstreptozotocin-Induced Diabetes in Male Wistar Rats. Journal of Applied Toxicology, 28, 806-813. http://dx.doi.org/10.1002/jat.1343

[31] Cullen, P., Eckardstein, A., Sours, S., Schulte, H. and Assman, G. (1999) Dyslipidaemia and Cardiovascular Risk in Diabetes. Diabetes, Obesity and Metabolism, 1, 189-198. http://dx.doi.org/10.1046/j.1463-1326.1999.00030.X

[32] Sout, R.W. (2005) Diabetes and Athroesclerosis. Biomedicine \& Pharmacotherapy, 47, 1-2. http://dx.doi.org/10.1016/0753-3322(93)90029-K

[33] Ahmed, R.G. (2005) The Physiological and Biochemical Effect of Diabetes on the Balance between Oxidative Stress and Antioxidant Defence System. Medical Journal of Islamic World Academy of Sciences, 15, 31-42.

[34] Kakkar, R., Kaira, J., Mantha, S.V. and Prasad, K. (1999) Lipidperoxidation and Activity of Antioxidant Enzymes in Diabetic Rats. Molecular and Cellular Biochemistry, 151, 113-119. http://dx.doi.org/10.1007/BF01322333

[35] Desco, M.C., Asensi, M., Marquez, R., Martinez-Valls, J., Vento, M., Pallardo, F.V., et al. (2002) Xanthine Oxidase Is Involved in Free Radical Production in Type 1 Diabetes: Protection by Allopurinol. Diabtes, 51, 1118-1124.

[36] Ronco, C., Grammaticopoulos, S., Rosner, M., Decal, M., Soni, S., Lentini, P., et al. (2010) Oliguria, Creatinine and Other Biomarkers of Acute Kindney Injury. Contributions to Nephrology, 164, 118-127. http://dx.doi.org/10.1159/000313725

[37] Cerieello, A., Morocutti, A., Franceschina, M., Quagliaro, L., Moro, M., Damante, G., et al. (2000) Defective Intracellular Antioxidant Enzyme Production in Type 1 Diabetic Patients with Nephropathy. American Diabetes Association, 49, 2170-2177.

[38] Unger, R.H. and Orci, L. (1981) Glucagon and the Cell. 11Physiology and Pathophysiology. The New England Journal of Medicine, 304, 1575-1580. http://dx.doi.org/10.1056/NEJM198106253042604 


\section{List of Abbreviations}

STZ: Streptozotocin.

WHO: World Health Organization.

DM: Diabetes Mellitus.

ROS: Reactive Oxygen Species.

LDL: Low-Density Lipoproteins.

VLDL: Very Low-Density Lipoprotein.

HDL: High-Density Lipoprotein.

HP: Lipid Hydroperoxide.

$\mathrm{H}_{2} \mathrm{O}_{2}$ : Dihydroperoxidase.

SOD: Superoxide Dismutase.

NADH:Nicotinamide Adenine Dinuleotide.

NBT: Nitro Blue Tetrazolium.

GSH-Px: Glutathione Peroxide.

S.D.: Standard Deviation.

NADPH: Nicotinamide Phosphate Dinucleotide.

ANOVA: Analysis of Variance

LACAT: Lecithin Cholesterol Acyltransferase.

BG: Blood Glucose.

$\left(\mathrm{O}^{2}\right)$ : Superoxide Anions. 